\title{
Heat and power load dispatching considering energy storage of district heating system and electric boilers
}

\author{
Xianzheng HUANG ${ }^{1}$, Zhaofeng XU ${ }^{1}$, Yong $\mathrm{SUN}^{1,2}$, Yali XUE ${ }^{1}{ }^{\mathbb{D}}$, \\ Zhe WANG ${ }^{1}$, Zhijun IIU $^{2}$, Zhenyuan LI $^{2}$, Weidou NI ${ }^{1}$
}

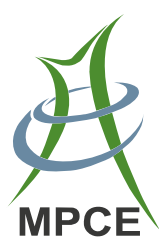

\begin{abstract}
As one of promising clean and low-emission energy, wind power is being rapidly developed in China. However, it faces serious problem of wind curtailment, particularly in northeast China, where combined heat and power (CHP) units cover a large proportion of the district heat supply. Due to the inherent strong coupling between the power and the heat load, the operational flexibility of CHP units is severely restricted in winter to meet the heat supply demand, which imparts considerable stress on the
\end{abstract}

CrossCheck date: 7 September 2017

Received: 7 December 2016/Accepted: 10 September 2017/ Published online: 18 January 2018

(C) The Author(s) 2018. This article is an open access publication

$\triangle$ Yali XUE

xueyali@tsinghua.edu.cn

Xianzheng HUANG

huangxz425@sina.com

Zhaofeng XU

xuzhaofeng@tsinghua.edu.cn

Yong SUN

sunyong_hit@163.com

Zhe WANG

zhewang@tsinghua.edu.cn

Zhijun LIU

liuzhijun1964@163.com

Zhenyuan LI

lizhenyuan1978@163.com

Weidou NI

niwd@tsinghua.edu.cn

1 Department of Energy and Power Engineering, State Key Lab of Power Systems, Tsinghua University, Beijing 100084, China

2 State Grid Jilin Electric Power Co., Ltd., Changchun 130021, China wind power connection to the grid. To promote the integration of wind power and enhance the flexibility of CHP units, this paper presented a method of heat and power load dispatching by exploring the energy storage ability of electric heating boilers and district heating systems. The optimization results indicate that the proposed method can integrate additional wind power into the grid and reduce the coal consumption of CHP units over the optimized period. Furthermore, the thermal inertia of a district heating system is found to contribute more to the reduction of coal consumption, whereas the electric heating boilers contribute to lower wind curtailment.

Keywords Wind power integration, Combined heat and power, Electric heating boiler, Thermal inertia

\section{Introduction}

China currently ranks as the world's largest emitter of greenhouse gases. In 2013, the $\mathrm{CO}_{2}$ emissions of China were almost 10 billion metric tons, accounting for $29 \%$ of the world's total emissions [1]. Facing increasing pressure to reduce $\mathrm{CO}_{2}$ emissions, China has announced an intention to constrain its $\mathrm{CO}_{2}$ emissions peak to approximately 2030 [2]. Wind power, constituting clean and low-carbon energy, is being rapidly developed in China. In 2010, China achieved the world's largest installed wind power capacity with $41.8 \mathrm{GW}$ [3], which increased to $147.7 \mathrm{GW}$ by the end of 2015 [4]. In wind-rich regions such as Jilin Province, located in Northeast China, the capacity of installed wind power is almost $40 \%$ of the peak load [5]. According to China's medium- and long-term renewable energy development plan [6], the total installed wind power capacity of China is planned to reach $200 \mathrm{GW}$ in 2020 . 
However, wind power in China, particularly in Northeast China, is facing a serious problem of wind curtailment [7]. In 2015, the annual wind curtailment ratio of Jilin province was as high as $32 \%$ [8]. The main reason is that more than $70 \%$ of the heating load in winter is supplied by centralized coal-fired combined heat and power (CHP) units, the electricity generation of which is severely restricted by their heat load [9], leaving little space for integrating wind power. Consequently, even during the offpeak hours of winter, the CHP units still cannot reduce sufficient power generation in order to meet the heating demand. The strong coupling between power and heat load restricts the operational flexibility of CHP units and causes severe wind curtailment [10]. This restriction has become a bottleneck for the continual development of China's wind power.

To integrate additional wind power into the grid, an effective method is to introduce additional heat suppliers into the heating system to decouple the power from the heat supply. References [11] and [12] proposed a system using electric boilers with heat storage tanks and demonstrated that this system could make a contribution to consume additional wind electricity. The electric boilers could increase the wind electricity consumption and enhance the flexibility of CHP units by replacing part of the heat produced by CHP units. Reference [13] developed a dispatch model to optimize the heat and power production from multiple sources, including CHP units, electric boilers, wind power and conventional units. This study demonstrated that electric boilers with heat storage tanks were effective at reducing wind curtailment and primary energy consumption. Reference [14] also introduced electric boilers and developed a stochastic partial equilibrium model of the power system. The results showed that the electric boilers could replace part of the heat production of oil-fired heat boilers and CHP plants and were beneficial for the integration of wind power and fuel saving. Furthermore, electric boilers and heat pumps have also been reported [15-22] to promote wind power integration. Reference [23] described a combination of electric boilers and wind generators that exhibited satisfactory performance in integrating wind power.

In addition to the use of heating equipment, the substantial energy storage potential existing in the district heating network has recently gained much attention. B. Qin et al $[24,25]$ found that fluctuations of supply water temperature in the main pipe network have a limited influence on the indoor temperature; thus, the thermal inertia of a heating network can be integrated to increase the flexibility of CHP units and reduce wind curtailment. In [7], the thermal inertia of indoor air and thermal comfort of end users were considered to reduce the heat dependence of CHP units and facilitate energy conservation. With the goal of minimizing the operational cost, W. Ji [26] developed an optimization model to use additional wind energy in which the inertia of a heating network was also involved. However, in the research of grid optimization, the two major methods of electric heating units and the thermal inertia of heating networks have not been compared simultaneously. Additionally, the models of thermal inertia of heating networks used in current research typically do not consider the heat storage ability of buildings, which is a critical factor in heat storage.

To promote the integration of wind power in Northeast China, this paper presents an optimization method for heat and electricity joint dispatching in which the electric boilers and the thermal inertia of the heating network and buildings are considered. Here, the electric boilers are used as wind power consumers and additional heat sources, while the thermal inertia of the pipelines and the buildings is analyzed using a detailed model to reflect the thermal inertia of the building structure, indoor air, and pipelines as well as the delay of water flow. In addition, the thermal comfort of end users in different time sections of the day is also considered to take advantage of the fluctuation of wind power and enhance the flexibility of CHP units.

This paper is organized as follows. In Section 2, the structure of the heat and electricity joint optimization model is illustrated. The mathematical model of electricity and heat supply is described in Section 3. The impact of introducing electric boilers and considering the thermal inertia of a heating network and buildings is illustrated by case studies in Section 4, and the results are discussed in Section 5. Finally, the conclusions are given in Section 6.

\section{Energy system and assumptions}

The energy system is presented in Fig. 1. The electricity is generated by CHP units and a wind turbine and then transferred to the end users by the grid. It is essential to satisfy the electricity demand all the time of a day. The theoretical wind power generation load is predicted through wind and weather conditions, and the wind power used to supply power and heat does not exceed the theoretical value.

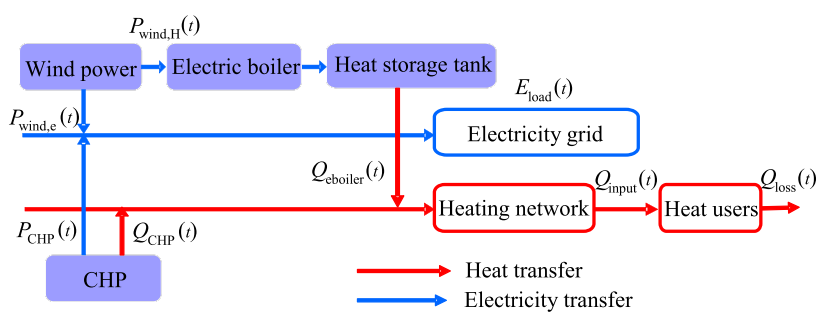

Fig. 1 Illustration of the energy system 
In heat transfer systems (see Fig. 2), heat is supplied by CHP units and electric boilers equipped with heat storage tanks. The heat storage tanks can store surplus wind power by heating water during off-peak hours in order to replace a proportion of the CHP heat production, increasing their flexibility. It is assumed that the power used by electric boilers comes entirely from wind energy. The heat sources, both electric boilers and CHP units, produce hot water or steam and heat the water in the main pipeline network through heat exchanger stations. The temperature of the supply water in the main pipeline network can be adjusted by changing the extraction flow rate of heating steam from the CHP and the supply water temperature from the electric boiler; the water flow rate in the main pipeline is assumed to be stable. In the main pipe network, circulating hot water is driven by pumps to heat up the branch pipe network through secondary heat exchangers. Subsequently, the hot water is transported to the end users, warming the buildings in general. The heat demand is determined from the outdoor temperature and the comfort requirements of end users over different times during the day.

\section{Mathematical model}

\subsection{Objective function}

Since wind power does not release $\mathrm{CO}_{2}$ directly, to realize energy saving and $\mathrm{CO}_{2}$ mitigation in such energy systems, the optimization objective of our research is to minimize the coal consumption of CHP units, expressed as:

$\operatorname{Coal}_{\text {sum }}=\sum_{t=1}^{T} \sum_{i=1}^{N} \operatorname{Coal}(t, i)$

where $N$ is the number of CHP units; Coal $_{\text {sum }}$ is the total coal consumption of all CHP units during the optimization period $T$; $\operatorname{Coal}(t, i)$ is the coal consumption of CHP unit $i$ at time $t$, which can be calculated as:

$\operatorname{Coal}(t, i)=a P_{\mathrm{CHP}}(t, i)+b Q_{\mathrm{CHP}}(t, i)+c$ where $P_{\mathrm{CHP}}(t, i)$ and $Q_{\mathrm{CHP}}(t, i)$ are the gross power output and the heat supply of CHP unit $i$ at time $t$, respectively; $a$, $b$ and $c$ are the coefficients.

\subsection{Constraints}

The model is subjected to physical and operating constraints that include the electricity demand, feasible operation ability of CHP units, wind power generation capacity, the characteristics of electric boilers with a heat storage tank and comprehensive district heating systems.

\subsubsection{Electricity balance}

Electricity is produced by wind power and CHP units and transferred to end users through the grid. The electricity load is transiently balanced:

$$
\begin{aligned}
E_{\text {load }}(t)= & (1-\alpha)\left[P_{\text {wind }, \mathrm{e}}(t)\left(1-\beta_{\text {wind }}\right)\right. \\
& \left.+\sum_{i}^{N} P_{\mathrm{CHP}}(t, i)\left(1-\beta_{\mathrm{CHP}}\right)\right]
\end{aligned}
$$

where $E_{\text {load }}(t)$ is the total electricity demand of the grid; $P_{\text {wind,e }}(t)$ is the gross output of wind power integrated into the grid; $\alpha$ is the line loss ratio; $\beta_{\text {wind }}$ and $\beta_{\mathrm{CHP}}$ are the auxiliary power ratio of wind power and CHP units, respectively.

\subsubsection{CHP units}

3.2.2.1 Feasible operation scope For a CHP unit, the electricity and heat generation are coupled, implying that the total power output and heat output is mutually restricted (see Fig. 3); the relationship is described in (4) and (5):

$P_{\text {min }}\left(Q_{\mathrm{CHP}}(t, i)\right)<P_{\mathrm{CHP}}(t, i)<P_{\max }\left(Q_{\mathrm{CHP}}(t, i)\right)$
$Q_{\text {min }}\left(P_{\mathrm{CHP}}(t, i)\right)<Q_{\mathrm{CHP}}(t, i)<Q_{\max }\left(P_{\mathrm{CHP}}(t, i)\right)$

where $P_{\min }\left(Q_{\mathrm{CHP}}(t, i)\right)$ and $P_{\max }\left(Q_{\mathrm{CHP}}(t, i)\right)$ are the minimum and maximum gross power output, respectively, of CHP unit $i$ when its heat output is equal to $Q_{\mathrm{CHP}}(t, i)$; $Q_{\text {min }}\left(P_{\mathrm{CHP}}(t, i)\right)$ and $Q_{\max }\left(P_{\mathrm{CHP}}(t, i)\right)$ are the minimum and

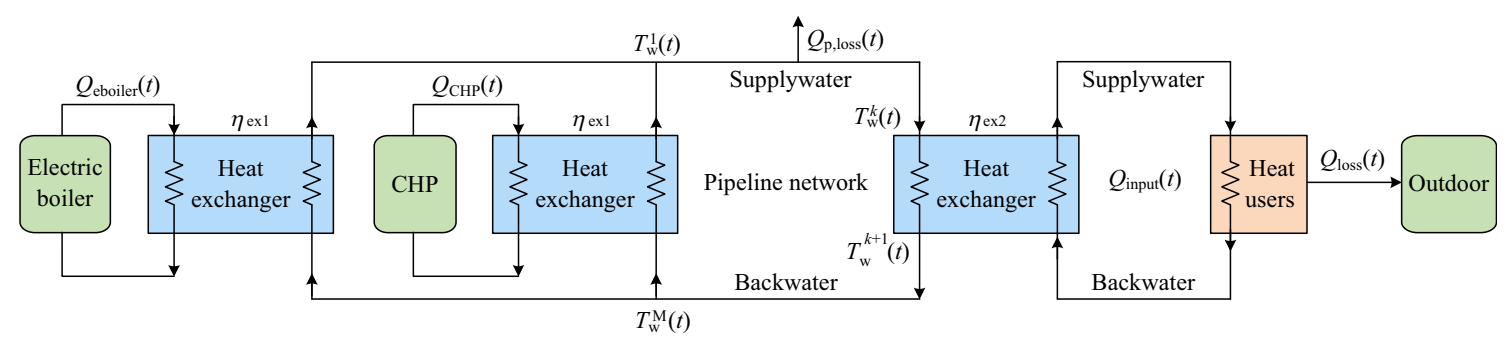

Fig. 2 Illustration of the heat transfer system 


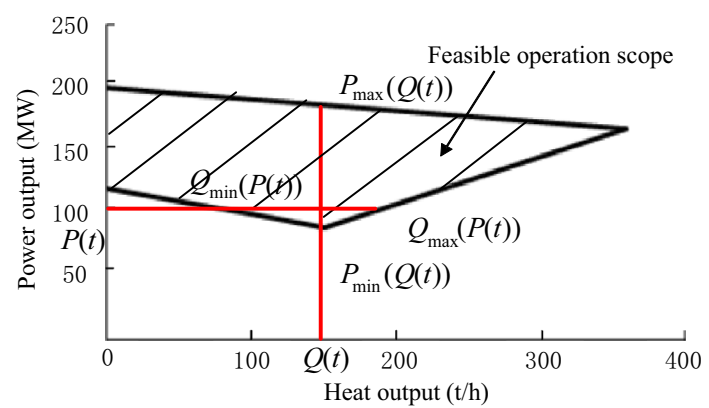

Fig. 3 Feasible operation scope of CHP units

maximum heat output, respectively, of CHP unit $i$ when its gross power output is equal to $P_{\mathrm{CHP}}(t, i)$.

3.2.2.2 Ramping constraints The ramping constraints are also considered; these restrict the incremental and decremental speed of the power output of CHP units within certain limits for safety:

$P_{\mathrm{CHP}}(t, i)-P_{\mathrm{CHP}}(t+1, i) \leq \Delta P_{\text {down }}$

$P_{\mathrm{CHP}}(t+1, i)-P_{\mathrm{CHP}}(t, i) \leq \Delta P_{\text {up }}$

where $\Delta P_{\text {down }}$ is the decremental speed limit and $\Delta P_{\text {up }}$ is the incremental speed limit.

\subsubsection{Wind power}

In general, the available wind power output can be predicted based on the wind and weather conditions. However, some of the wind power will be abandoned if it cannot be integrated into the grid. In this paper, considering wind curtailment, the total effective wind output, i.e., the power integrated to the grid and power used to heat electric boilers, should be not greater than the available wind power output, which is described in (8):

$P_{\text {wind }}(t) \geq P_{\text {wind }, \mathrm{e}}(t)+P_{\text {wind }, \mathrm{H}}(t)$

where $P_{\text {wind }}(t)$ is the available wind power output; $P_{\text {wind,e }}(t)$ is the wind power integrated to the grid and $P_{\text {wind,H }}(t)$ represents the wind power used to heat electric boilers.

\subsubsection{Electric boilers with heat storage tanks}

In this paper, electric boilers are equipped with heat storage tanks (see Fig. 4), which can store energy by heating water in tanks when there is surplus wind power. When heat is required, hot water in the tanks can provide heat to the heating network. The heat balance of electric boilers with heat storage tanks can be described using (9) and (10).

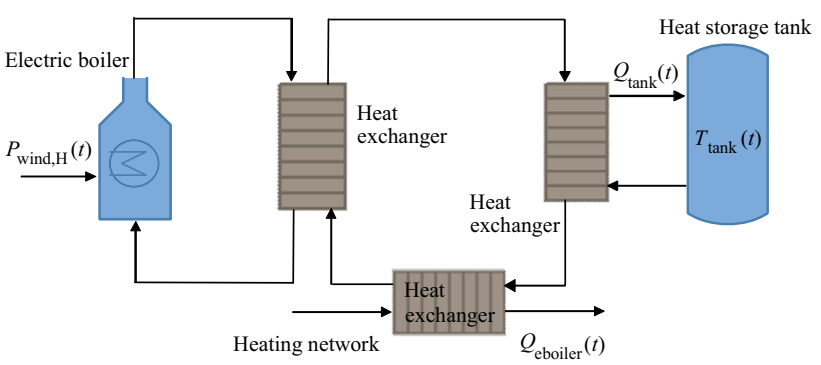

Fig. 4 Illustration of electric boilers with heat storage tanks

$P_{\text {wind }, \mathrm{H}}(t) \eta_{\text {eboiler }} \eta_{\text {ex } 0}=Q_{\text {eboiler }}(t)+Q_{\text {tank }}(t)$

$Q_{\mathrm{tank}}(t) \eta_{\mathrm{ex} 0} \Delta t=M_{\mathrm{tank}} c_{\mathrm{w}}\left[T_{\mathrm{tank}}(t+1)-T_{\mathrm{tank}}(t)\right]$

where $Q_{\text {eboiler }}(t)$ is the heat supplied to the main heating network by electric boilers; $Q_{\operatorname{tank}}(t)$ is the heat supplied to the heat storage tanks; $M_{\mathrm{tank}}$ is the water mass in the heat storage tanks; $T_{\operatorname{tank}}(t)$ is the water temperature in the tanks at time $t ; c_{\mathrm{w}}$ is the specific heat capacity of water; $\Delta t$ is the time step; $\eta_{\text {eboiler }}$ and $\eta_{\mathrm{ex} 0}$ are the efficiency of the electric boilers and heat exchangers, respectively.

The water temperature in tanks is limited by the following constraints in (11)-(13):

$T_{\text {tank }}(t+1)-T_{\text {tank }}(t) \leq \Delta T_{\text {up }}$

$T_{\text {tank }}(t)-T_{\text {tank }}(t+1) \leq \Delta T_{\text {down }}$

$T_{\text {tank }}(t) \leq T_{\text {tank,max }}$

where $T_{\text {tank,max }}$ is the highest water temperature in the tanks and $\Delta T_{\text {up }}$ and $\Delta T_{\text {down }}$ are the maximum temperature incline and decline speed, respectively.

\subsubsection{Heating network}

We idealize the heating network as a pipeline loop with constant diameter, in which heat is transferred from heat sources (i.e., CHP units and electric boilers) to water in the pipeline, then from water to heat sinks (i.e., heat users) when the water flows from the heat sources to the heat sinks (see Fig. 2).

If we ignore the variation of water density in pipeline, the flow is taken as one-dimensional incompressible flow. We also assume that the water flow rate in the pipeline is constant and the energy input/output changes only the water temperature. The pipeline consists of steel tube and insulation layer, which are assumed to be isotropic (see Fig. 5). Because the insulation layer has a large heat resistance and small heat capacity, we ignore heat storage in the insulation layer. Furthermore, we assume that the temperature of the surroundings does not change.

Therefore, the dynamic heat conservation of the water and pipeline are described by (14)-(16): 


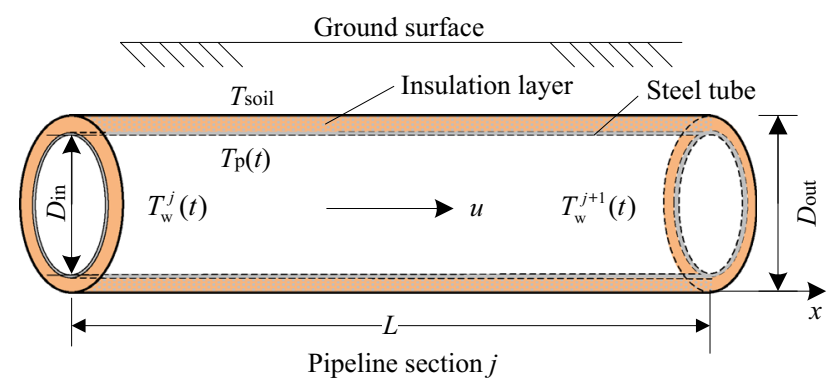

Fig. 5 Illustration of pipeline section

$$
\begin{aligned}
& \frac{\partial T_{\mathrm{w}}}{\partial t}+u \frac{\partial T_{\mathrm{w}}}{\partial x}=H\left(T_{\mathrm{p}}-T_{\mathrm{w}}\right) \\
& \frac{\partial T_{\mathrm{p}}}{\partial t}=H_{1}\left(T_{\mathrm{w}}-T_{\mathrm{p}}\right)+H_{2}\left(T_{\text {soil }}-T_{\mathrm{p}}\right) \\
& \left\{\begin{array}{l}
H=\frac{\alpha_{\mathrm{w}} \pi D_{\text {in }}}{S_{\mathrm{w}} c_{\mathrm{w}} \rho_{\mathrm{w}}} \\
H_{1}=\frac{\alpha_{\mathrm{w}} \pi D_{\text {in }}}{S_{\mathrm{p}} c_{\mathrm{p}} \rho_{\mathrm{p}}} \\
H_{2}=\frac{\alpha_{\text {soil }} \pi D_{\text {out }}}{S_{\mathrm{p}} c_{\mathrm{p}} \rho_{\mathrm{p}}}
\end{array}\right.
\end{aligned}
$$

where $T_{\mathrm{w}}, T_{\mathrm{p}}$ and $T_{\text {soil }}$ are the temperature of water, pipelines and soil, respectively; $u$ is the water flow speed at the cross-section; $\alpha_{\mathrm{w}}$ is the heat transfer coefficients between the water and pipe; $\alpha_{\text {soil }}$ is the heat transfer coefficient between the insulation and soil; $D_{\text {in }}$ and $D_{\text {out }}$ are the inner and outer diameter of pipelines, respectively; $S_{\mathrm{w}}$ and $S_{\mathrm{p}}$ represent the cross-sectional area of the water flow and pipelines, respectively; $c_{\mathrm{w}}$ and $c_{\mathrm{p}}$ are the specific heat capacity of the water and pipelines, respectively; $\rho_{\mathrm{w}}$ and $\rho_{\mathrm{p}}$ are the density of the water and pipelines, respectively.

3.2.5.1 Heat balance of water We divide the pipeline into $M$ sections, each with a length of $L$. Therefore, using the first-order upwind difference, the dynamic heat conservation of water, i.e., (14), can be described by (17)-(19):

$u S_{\mathrm{w}} c_{\mathrm{w}} \rho_{\mathrm{w}}\left[T_{\mathrm{w}}^{j+1}(t)-T_{\mathrm{w}}^{j}(t)\right] \Delta t=Q_{\mathrm{water}}(t)+Q_{\mathrm{w}, \text { loss }}(t)$

$Q_{\mathrm{w}, \text { loss }}(t)=\alpha_{\mathrm{w}} \pi D_{\text {in }} L\left[T_{\mathrm{w}}^{j}(t)-T_{\mathrm{p}}^{j}(t)\right] \Delta t$

$Q_{\text {water }}(t)=c_{\mathrm{w}} \rho_{\mathrm{w}} S_{\mathrm{w}} L\left[T_{\mathrm{w}}^{j}(t+1)-T_{\mathrm{w}}^{j}(t)\right]$

where $T_{\mathrm{w}}^{j}(t)$ and $T_{\mathrm{p}}^{j}(t)$ are the temperature of the water and pipelines, respectively, at an axial position of $j$ and time $t$; $Q_{\text {water }}(t)$ is the heat stored by the water; $Q_{\mathrm{w}, \text { loss }}(t)$ represents the heat transfer between water and pipelines; $\Delta t$ is the time step; $L$ is the section length of the pipelines.
3.2.5.2 Heat balance of pipelines We ignore the variation of the soil temperature and the axial variation of the pipeline temperature and convert the dynamic heat conservation of pipelines, i.e., (15), into (20) and (21), using the first-order upwind differences:

$Q_{\mathrm{w}, \operatorname{loss}}(t)-Q_{\mathrm{p}, \operatorname{loss}}(t)=c_{\mathrm{p}}\left[T_{\mathrm{p}}^{j}(t+1)-T_{\mathrm{p}}^{j}(t)\right] \rho_{\mathrm{p}} S_{\mathrm{p}} L$

$Q_{\mathrm{p}, \text { loss }}(t)=\alpha_{\text {soil }} \pi D_{\text {out }} L\left[T_{\mathrm{p}}^{j}(t)-T_{\text {soil }}\right] \Delta t$

where $Q_{\mathrm{p}, \text { loss }}(t)$ is the heat transfer between the pipelines and soil.

3.2.5.3 Heat supply of a heating network The heat supply of pipelines, which consists of the heat provided by the CHP units and electric boilers, heats the backwater to form the new supply water, i.e., by changing the water temperature of the first section of heating network. Therefore, the heat supply of the heating network can be described by (22):

$$
\begin{aligned}
& {\left[\sum_{i}^{N} Q_{\mathrm{CHP}}(t, i)+Q_{\text {eboiler }}(t)\right] \eta_{\text {ex } 1}} \\
& =u S_{\mathrm{w}} c_{\mathrm{w}} \rho_{\mathrm{w}}\left[T_{\mathrm{w}}^{1}(t+1)-T_{\mathrm{w}}^{M}(t)\right]
\end{aligned}
$$

where $\eta_{\mathrm{ex} 1}$ is the efficiency of the primary heat exchanger of the main heating network; $T_{\mathrm{w}}^{1}(t+1)$ is the temperature of the supply water at time $t+1 ; T_{\mathrm{w}}^{M}(t)$ is the temperature of the back water at time $t$.

3.2.5.4 Temperature constraints of the heating network Temperature constraints exist in all heating networks, and the temperatures of the supply water and back water are restricted to certain ranges, as described by (23) and (24):

$T_{\mathrm{w}, \min }^{\mathrm{s}}<T_{\mathrm{w}}^{j}(t)<T_{\mathrm{w}, \max }^{\mathrm{s}}$ for supply water pipe

$T_{\mathrm{w}, \min }^{\mathrm{b}}<T_{\mathrm{w}}^{j}(t)<T_{\mathrm{w}, \text { max }}^{\mathrm{b}}$ for return water pipe

where $T_{\mathrm{w}, \min }^{\mathrm{s}}$ and $T_{\mathrm{w}, \max }^{\mathrm{s}}$ are the minimum and maximum temperature of the supply water, respectively; $T_{\mathrm{w}, \min }^{\mathrm{b}}$ and $T_{\mathrm{w}, \max }^{\mathrm{b}}$ are the minimum and maximum temperature of the back water, respectively.

\subsubsection{Buildings}

3.2.6.1 Heat balance of indoor air In the winter of Northeast China, heat is used primarily to warm buildings, which can be considered a closed systems if we ignore air exchange from opening/closing doors (see Fig. 6). Therefore, the dynamic heat balance of indoor air is described as (25). Using one-order upwind differences, (25) can be described using (26)-(28). 
$I_{\text {air }} \frac{\mathrm{d} T_{\text {in }}(t)}{\mathrm{d} t}=Q_{\text {input }}(t)-Q_{\text {wall }}(t)$

$c_{\text {air }} h s \rho_{\text {air }}\left[T_{\text {in }}(t+1)-T_{\text {in }}(t)\right]=\left[Q_{\text {input }}(t)-Q_{\text {wall }}(t)\right] \Delta t$

$Q_{\text {input }}(t)=u S_{\mathrm{w}} c_{\mathrm{w}} \rho_{\mathrm{w}}\left[T_{\mathrm{w}}^{K}(t)-T_{\mathrm{w}}^{K+1}(t)\right] \eta_{\mathrm{ex} 2}$

$Q_{\text {wall }}(t)=\alpha_{\text {in }} b_{\text {in }} h s\left[T_{\text {in }}(t)-T_{\text {wall,in }}(t)\right]$

where $Q_{\text {input }}(t)$ is the heat input from the heating network; $Q_{\text {wall }}(t)$ is the heat transferred from the indoor air to the walls; $I_{\text {air }}$ is the heat capacity of the indoor air; $T_{\text {in }}(t)$ is the indoor air temperature; $h$ is the height of each floor; $s$ is the floor area of the building; $c_{\text {air }}$ is the specific heat capacity of air; $\rho_{\text {air }}$ is the density of air; $T_{\mathrm{w}}^{K}(t)$ is the temperature of the pipeline water that heats the buildings via secondary heat exchangers; $\eta_{\mathrm{ex} 2}$ is the heat transfer efficiency of the secondary heat exchangers; $b_{i \mathrm{n}}$ is the shape coefficient of the inner walls, representing the ratio between the inner wall area and volume of buildings; $\alpha_{\mathrm{in}}$ is the heat transfer coefficient between the indoor air and walls; $T_{\text {wall,in }}(t)$ represents the temperature of the inner walls.

3.2.6.2 Heat balance of walls The walls of buildings have non-negligible heat storage capacity. The dynamic heat balance of walls is described as (29). In addition, this balance can be described using (30)-(32) in terms of oneorder upwind differences:

$$
\begin{gathered}
I_{\text {wall }} \frac{\mathrm{d} T_{\text {wall }}(t)}{\mathrm{d} t}=Q_{\text {wall }}(t)-Q_{\text {loss }}(t) \\
c_{\text {wall }} b_{\text {in }} h s \delta \rho_{\text {wall }}\left[T_{\text {wall }}(t+1)-T_{\text {wall }}(t)\right] \\
=\left[Q_{\text {wall }}(t)-Q_{\text {loss }}(t)\right] \Delta t \\
Q_{\text {loss }}(t)=\alpha_{\text {out }} b_{\text {out }} h s\left[T_{\text {wall,out }}(t)-T_{\text {out }}(t)\right] \\
T_{\text {wall }}(t)=\left[T_{\text {wall,in }}(t)+T_{\text {wall,out }}(t)\right] / 2
\end{gathered}
$$

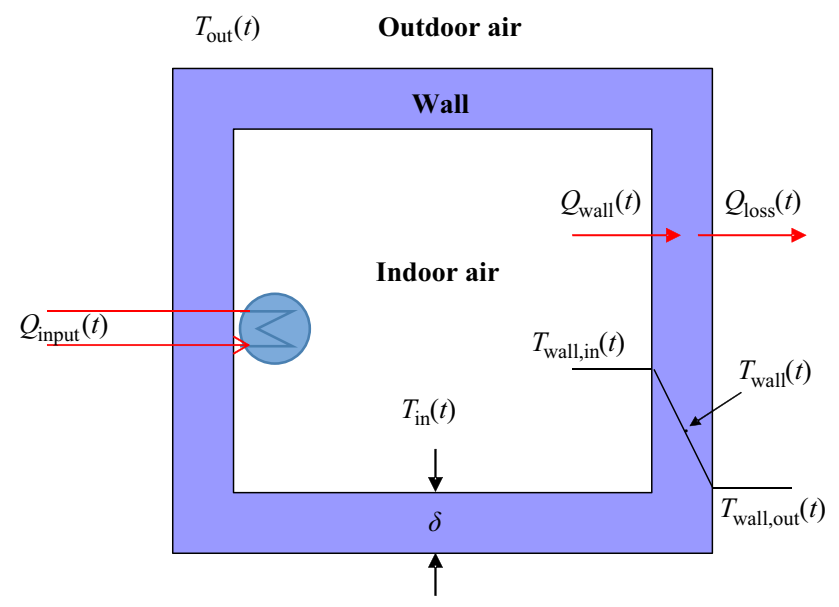

Fig. 6 Idealization of a building where $Q_{\text {loss }}(t)$ is the heat transferred from the walls to the outdoor air; $I_{\text {wall }}$ is the heat capacity of the walls; $T_{\text {wall }}(t)$ is the average temperature of the walls, see (32); $c_{\text {wall }}$ is the specific heat capacity of the walls; $\rho_{\text {wall }}$ is the density of the walls; $\delta$ is the wall thickness; $\alpha_{\text {out }}$ is the heat transfer coefficient between the outdoor air and the walls; $b_{\text {out }}$ is the shape coefficient of the outer walls, representing the ratio between the outer wall area and the building volume; $T_{\text {wall,out }}(t)$ represents the temperature of the outer walls; $T_{\text {out }}(t)$ is the outdoor air temperature.

\subsubsection{The comfortable temperature of end users}

The indoor air temperature should remain in a specific range for the comfort of end users. Over different time periods, end users may have different heat requirements. Therefore, we can use more surplus wind power if we assign different comfortable temperature limitations to different time zones. Consequently, the energy from surplus wind power can be stored within heat storage tanks or the heating network and buildings when a lower indoor temperature is acceptable, and can be released when additional heat is needed. The equations of comfort temperature of end users are provided by the following expressions:

$$
\begin{array}{ll}
T_{\text {in,min1 }} \leq T_{\text {in }}(t) \leq T_{\text {in,max }} & t_{1} \leq t \leq t_{2} \\
T_{\text {in,min2 }} \leq T_{\text {in }}(t) \leq T_{\text {in,max }} & t_{2} \leq t \leq t_{3}
\end{array}
$$

where $t_{1}, t_{2}$ and $t_{3}$ are different time points of one day; $T_{\mathrm{in}, \min 1}$ and $T_{\mathrm{in}, \min 2}$ are minimum indoor temperature limits in one day; $T_{\mathrm{in}, \max }$ is the maximum indoor temperature limit.

\subsection{Solving method}

The model proposed above is a mixed integer non-linear programming (MINLP) problem. Several methods have been developed to solve this problem, including branch and bound (BB), generalized benders decomposition (GBD), outer approximation with equality relaxation (OA/ER), among others. The DICOPT solver in GAMS based on the $\mathrm{OA} / \mathrm{ER}$ algorithm is used to solve the current problem. The detailed solution method of the OA/ER algorithm is described in [7].

\section{Case study}

Four case studies are applied to a day-ahead schedule problem, and based on the optimization results, the actual operational mode of wind power and CHP units can be adjusted with the goal of minimizing coal consumption. 
Table 1 Study cases

\begin{tabular}{lll}
\hline Case & $\begin{array}{l}\text { Electric boilers with } \\
\text { heat storage tanks }\end{array}$ & $\begin{array}{l}\text { Thermal inertia of heating } \\
\text { network and buildings }\end{array}$ \\
\hline Case 1 & N/A & N/A \\
Case 2 & $\sqrt{ }$ & N/A \\
Case 3 & N/A & $\sqrt{ }$ \\
Case 4 & $\sqrt{ }$ & $\sqrt{ }$ \\
\hline
\end{tabular}

Case 1 represents the reference case, which does not consider electric boilers or the thermal inertia of heating network or buildings. The thermal inertia of a heating network and buildings and the electric boilers using wind power are included separately in Cases 2 and 3, respectively. In Case 4, both factors are incorporated into the model. The four cases are summarized in Table 1.

\subsection{Wind power}

In the four cases, the installed capacity of wind power is $400 \mathrm{MW}$, which is approximately $1 / 10$ of the total installed wind power in one province of Northeast China. The hourly available output of wind power is derived and scaled down from the simulated wind power output in the province on January 10, 2014, and is set as the maximum theoretical wind power output in case study. The available power output curve shows a negative correlation with the electricity load.

As shown in Fig. 7, the available output of wind power is relatively large in the nighttime, when there is stronger wind, but decreases in the daytime, whereas the power load is typically high in the daytime. In addition, a 5\% auxiliary power ratio of wind power and a 5\% line loss ratio are considered in case study.

\subsection{CHP units}

In these cases, six sets of 200 MW CHP units are assumed to be in the system, representing almost $1 / 10$ of

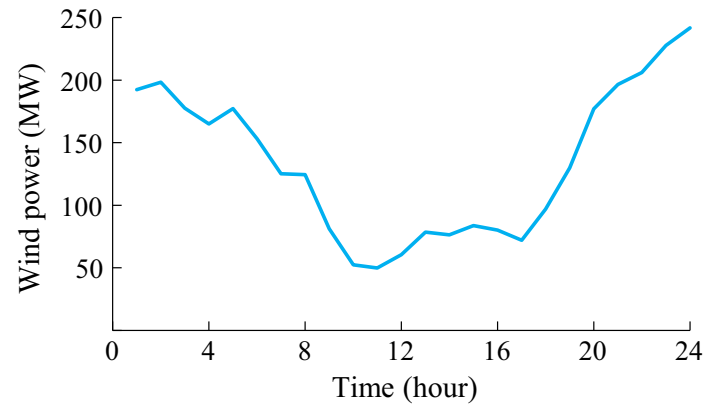

Fig. 7 Available output curve of wind power
Table 2 Parameters of CHP units

\begin{tabular}{lllllll}
\hline $\begin{array}{l}\text { Parameter } \\
\text { of CHP } \\
\text { units }\end{array}$ & $\begin{array}{l}\text { Capacity } \\
(\mathrm{MW})\end{array}$ & $\begin{array}{l}\text { Min } \\
\text { power } \\
\text { load } \\
(\mathrm{MW})\end{array}$ & $\begin{array}{l}\text { Max } \\
\text { heat } \\
\text { load } \\
(\mathrm{t} / \mathrm{h})\end{array}$ & \multicolumn{2}{l}{$\begin{array}{l}\text { Coal consumption } \\
\text { coefficient }\end{array}$} \\
\hline Value & 200 & 90 & 360 & 331.8 & 55.7 & -4634.0 \\
\hline
\end{tabular}

the total installed CHP capacity in this province. The detailed parameters of the units are shown in Table 2.

\subsection{Electric boilers and heat storage tanks}

The capacity of the electricity heat boilers is $15 \mathrm{MW}$, and they are equipped with four heat storage tanks whose maximum water storage is each $350 \mathrm{t}$. The electricity used by the heat boilers all comes from wind power, and the efficiency of the boiler system is assumed to be $95 \%$. Additionally, the temperatures of the supply and back water provided by electric boilers are $180^{\circ} \mathrm{C}$ and $70^{\circ} \mathrm{C}$, respectively.

\subsection{Electricity load}

The hourly electricity load is derived from the average grid load data in 2014 and is multiplied by a factor of 0.1 to match the installed generation capacity. As shown in Fig. 8, the electricity demand is low in the nighttime but high in the daytime, with a peak load of $821 \mathrm{MW}$.

\subsection{District heating system}

The district heating system is composed of CHP units, electric boilers, hot water pipelines and end users. In the main heating network, the water flow is $8000 \mathrm{~m}^{3} / \mathrm{h}$, and the heating distance is set as $13 \mathrm{~km}$. The parameters of the heating network and end users are listed in Tables 3 and 4.

The heat load is determined by the outdoor temperature and the thermal comfort temperature of the end users. The

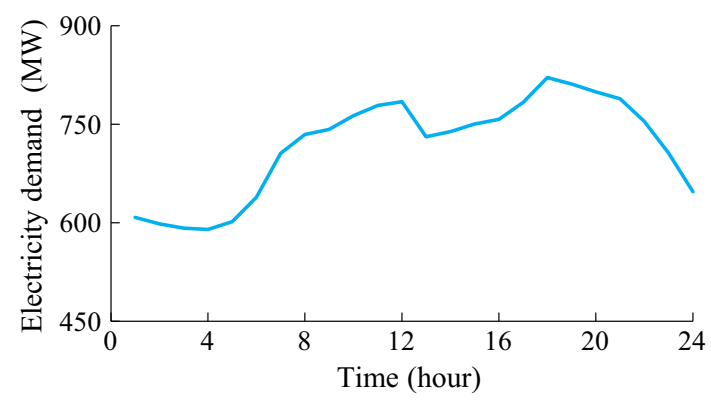

Fig. 8 Electricity demand curve 
Table 3 Parameters of the heating network

\begin{tabular}{ll}
\hline Parameters of heating network & Values \\
\hline Inner diameter of pipeline $(\mathrm{mm})$ & 1200 \\
External diameter of pipeline $(\mathrm{mm})$ & 1400 \\
Heat capacity of pipeline $(\mathrm{kJ} /(\mathrm{kg} \mathrm{K}))$ & 0.465 \\
Heat transfer coefficient between water and pipe $(\mathrm{kW} /$ & 1 \\
$\left.\quad\left(\mathrm{~m}^{2} \mathrm{~K}\right)\right)$ & 57 \\
Thickness of insulation $(\mathrm{mm})$ & 0.023 \\
Thermal conductivity of insulation $\left(\mathrm{kW} /\left(\mathrm{m}^{2} \mathrm{~K}\right)\right)$ & \\
\hline
\end{tabular}

Table 4 Parameters of the end users

\begin{tabular}{ll}
\hline Parameters of end users & Values \\
\hline Heating area $\left(\right.$ million $\left.\mathrm{m}^{2}\right)$ & 12 \\
Floor height $(\mathrm{m})$ & 2.8 \\
Heat capacity of building structure $(\mathrm{kJ} /(\mathrm{kg} \mathrm{K}))$ & 0.88 \\
Heat capacity of indoor air $\left(\mathrm{kJ} /\left(\mathrm{m}^{3} \mathrm{~K}\right)\right)$ & 1.297 \\
Heat transfer coefficient between indoor air and external & 3 \\
$\quad$ building structure $\left(\mathrm{W} /\left(\mathrm{m}^{2} \mathrm{~K}\right)\right)$ & \\
Thickness of building structure $(\mathrm{m})$ & 0.24 \\
Shape coefficient $\left(\mathrm{m}^{-1}\right)$ & 0.25 \\
Ratio between internal and external building structure & 2.6 \\
\hline
\end{tabular}

hourly outdoor temperature is selected from typical winter temperature data of Changchun, the capital of Jilin Province. The minimum thermal comfort temperature for end users is set to $16^{\circ} \mathrm{C}$ in the nighttime and $18^{\circ} \mathrm{C}$ in the daytime. The maximum thermal comfort temperature is set to $25^{\circ} \mathrm{C}$.

\section{Results and discussion}

\subsection{Power balance}

The hourly power balance for each case is shown in Fig. 9, and the electricity produced by CHP units and wind power for each case is shown in Fig. 10. Relative to Case 1, additional wind power in the other cases can be integrated in off-peak hours. In Case 1, the minimum power load of CHP units is limited due to the high heat output, leading to a wind curtailment ratio of $16.2 \%$, as shown in Fig. 11 .

When introducing electric boilers, the wind power curtailment is reduced by $282 \mathrm{MWh}$, and the wind curtailment ratio is $7.5 \%$. By contrast, the thermal inertia of the heating network decreases the wind curtailment ratio to $11.2 \%$, and $164 \mathrm{MWh}$ wind curtailment is reduced relative to Case 1. This finding indicates the high effectiveness of electric boilers in reducing wind curtailment relative to thermal
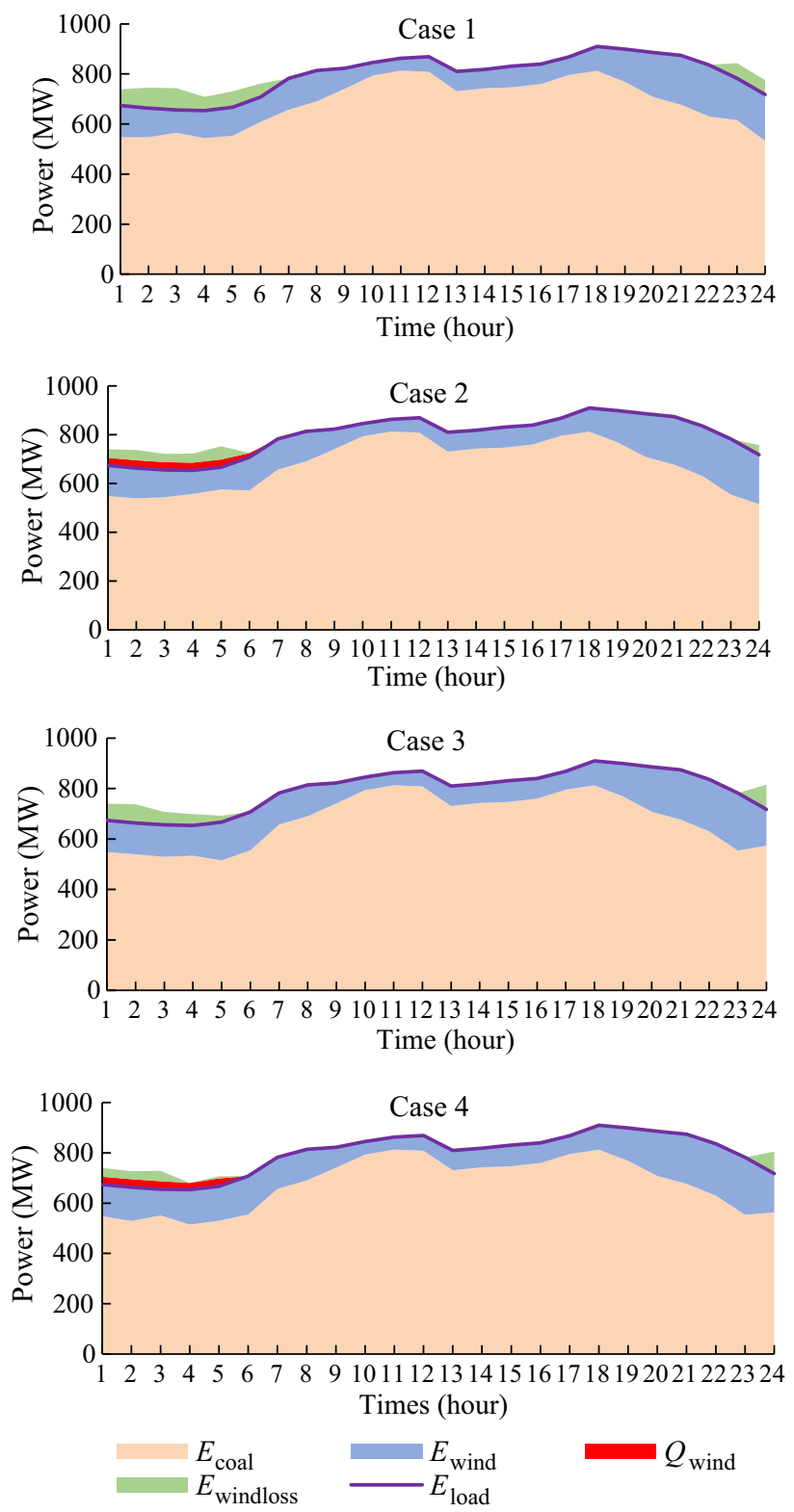

Fig. 9 Electricity balance for each case

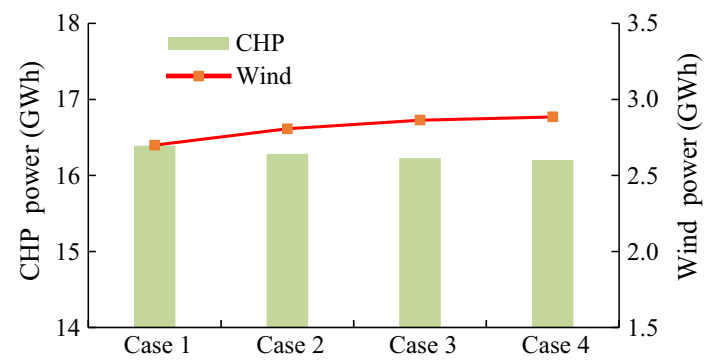

Fig. 10 Electricity dispatch for each case

inertia, the reason for which is that a proportion of wind power is used for heating in Case 2, consuming curtailed wind power directly. 


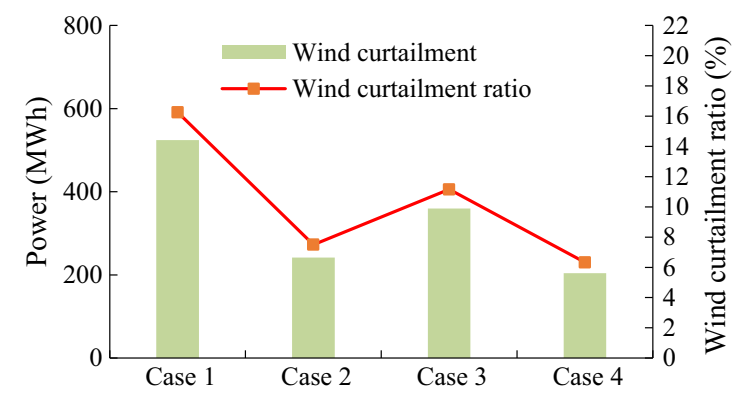

Fig. 11 Wind power curtailment for each case

In Case 4, CHP units produce $16.2 \mathrm{GWh}$ of electricity, which is the lowest of the four cases. In addition, the wind curtailment ratio reaches $6.3 \%$ of the total wind power production, indicating an improvement in reducing wind curtailment and increasing the flexibility of CHP units by combining electric boilers and heating network thermal inertia.

\subsection{Coal consumption}

Figure 12 shows the coal consumption of CHP units in one day for each case, according to which the coal consumption decreases gradually. Case 1 employs the original schedule without considering the electric boilers and thermal inertia. A high amount of coal is consumed in Case 1, reaching 5820 t per day. Relative to Case 1, Case 2 saves $40 \mathrm{t}$ of coal through the use of electric heating boilers. Also relative to Case 1, the coal consumption of Case 3 is reduced by $100 \mathrm{t}$, which shows that when considering the thermal inertia, a heating network offers a higher coal saving potential than that of electric boilers. Moreover, when the two factors are combined in Case 4, the system features the lowest coal consumption.

Even though the electric boilers appear to be more effective than thermal inertia at reducing wind curtailment according to Fig. 11, the latter method has a higher potential for reducing coal consumption. The wind curtailment is reduced by $283 \mathrm{MWh}$ and $164 \mathrm{MWh}$ in Cases 2 and 3 , respectively, relative to Case 1 . Consequently, 0.14

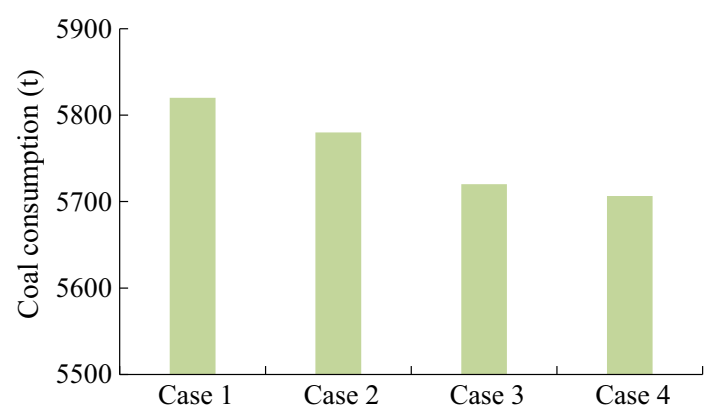

Fig. 12 Coal consumption for each case metric tons of coal can be saved when integrating $1 \mathrm{MWh}$ of wind power for considering electric boilers, and introducing the thermal inertia of a heating network can reduce $0.61 \mathrm{t}$ of coal by integrating $1 \mathrm{MWh}$ of wind power. The difference between the two solutions at reducing coal consumption emphasizes the low heating efficiency of electric boilers.

\subsection{Heat production}

As shown in Fig. 13, the CHP heat production in one day is 46340 GJ in Case 1 and 45756 GJ in Case 2. In Case 2, the electric boilers supply 597 GJ of heat. When introducing thermal inertia of the heating network, the CHP heat production drops to $40,790 \mathrm{GJ}$.

These results demonstrate that in Case 3, the thermal inertia of the heating network is intensively applied, which reduces the total heat supply by almost $12 \%$. The heat production of electric boilers in Case 4 is 523 GJ, less than that in Case 2. However, Case 4 achieves the lowest wind curtailment, because the combination of electric boilers and thermal inertia in Case 4 increases the flexibility of CHP units, making it possible to integrate additional wind power into the grid. Furthermore, although the coal consumption for heating in Case 4 is higher than that of Case 3 , the decrease in coal consumption from the electricity load reduction results in Case 4 featuring the smallest total coal consumption.

The total heat supply in the system is used primarily in two ways: heat storage in different mediums and heat loss. In Case 3, less heat is supplied than in Case 1 because the heat stored in different mediums is released to the system, offsetting part of the heat demand. The optimization time period in the model is 24 hours, indicating that to achieve the lowest coal consumption, the optimized result provides a method for CHP unit dispatching and simultaneously reduces wind curtailment. Since the outdoor temperature and the output of wind power vary considerably over each day, it is feasible that we can perform optimized dispatching of CHPs to reduce wind curtailment when the wind power is strong.

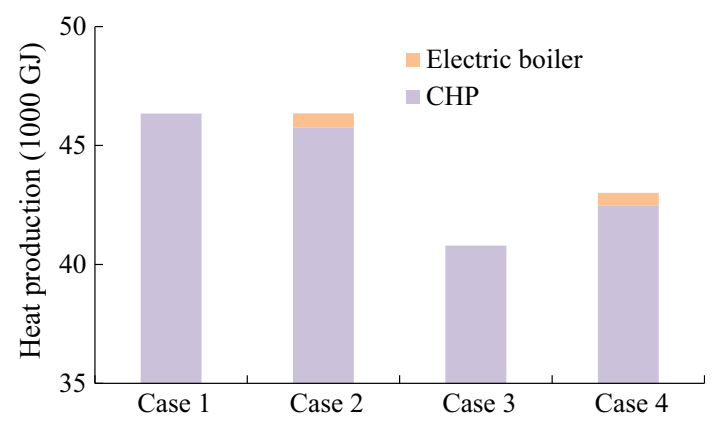

Fig. 13 Heat production for each case 
Table 5 The Balances of the results

\begin{tabular}{|c|c|c|c|c|}
\hline Parameter & Case 1 & Case 2 & Case 3 & Case 4 \\
\hline \multicolumn{5}{|l|}{ Grid (MWh) } \\
\hline Demand & 19091 & 19091 & 19091 & 19091 \\
\hline Generated by CHP & 16391 & 16284 & 16227 & 16224 \\
\hline Wind power to grid & 2699 & 2806 & 2863 & 2866 \\
\hline \multicolumn{5}{|l|}{ CHP units } \\
\hline Power(MWh) & 16391 & 16284 & 16227 & 16224 \\
\hline Heat(1000GJ) & 46.34 & 45.76 & 40.80 & 42.49 \\
\hline \multicolumn{5}{|l|}{ Wind power $(\mathrm{MWh})$} \\
\hline Available & 3224 & 3224 & 3224 & 3224 \\
\hline Generated & 2699 & 2980 & 2863 & 3019 \\
\hline To grid & 2699 & 2806 & 2863 & 2866 \\
\hline Wind to heat & 0 & 174 & 0 & 153 \\
\hline Curtailment & 524 & 241 & 360 & 204 \\
\hline Curtailment reduction & base & 283 & 164 & 320 \\
\hline Curtail ratio(\%) & 16.3 & 7.5 & 11.2 & 6.3 \\
\hline \multicolumn{5}{|l|}{ Heat (1000GJ) } \\
\hline Total heat supply & 46.34 & 46.36 & 40.8 & 43.01 \\
\hline By CHP & 46.34 & 45.76 & 40.8 & 42.49 \\
\hline By Electric Boiler & 0 & 0.6 & 0 & 0.52 \\
\hline \multicolumn{5}{|l|}{ Coal (t) } \\
\hline Coal consumption & 5820.2 & 5780 & 5720.1 & 5706.5 \\
\hline Coal saving & base & 40.2 & 100.1 & 113.7 \\
\hline Coal saving by electric boiler & 0 & 0.014 & 0 & 0.012 \\
\hline Coal saving by wind power & & 35.7 & 54.5 & 55.4 \\
\hline Coal saving by thermal inertial & 0 & 0 & 45.6 & 58.3 \\
\hline
\end{tabular}

The balances of the Grid, CHP units, wind power units, the heat supply, coal consumption and reduction are listed in Table 5 for Case 1-Case 4, which could clearly show the flow of substances and energy.

\subsection{Heat transport}

The temperature of supply water along the pipeline in Case 3 is shown in Fig.14. $T_{\mathrm{w} 1}, T_{\mathrm{w} 2}$ and $T_{\mathrm{w} 3}$ represent the supply water temperature at starting, middle and terminal point of the pipeline. It is obvious that the temperature decreases with water flows along the pipeline. There also

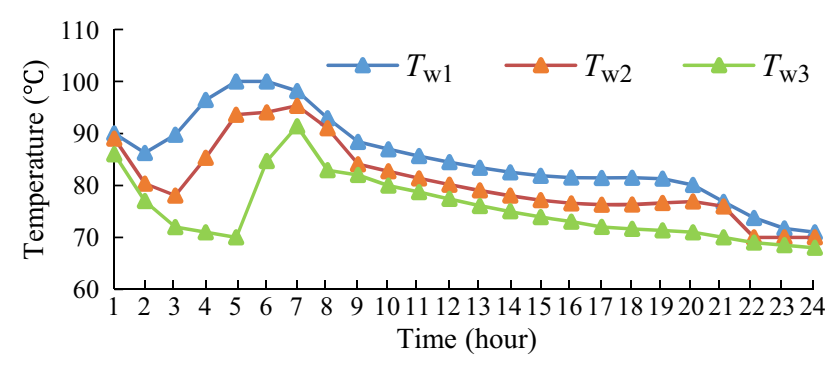

Fig. 14 Temperatures along the pipeline in Case 3

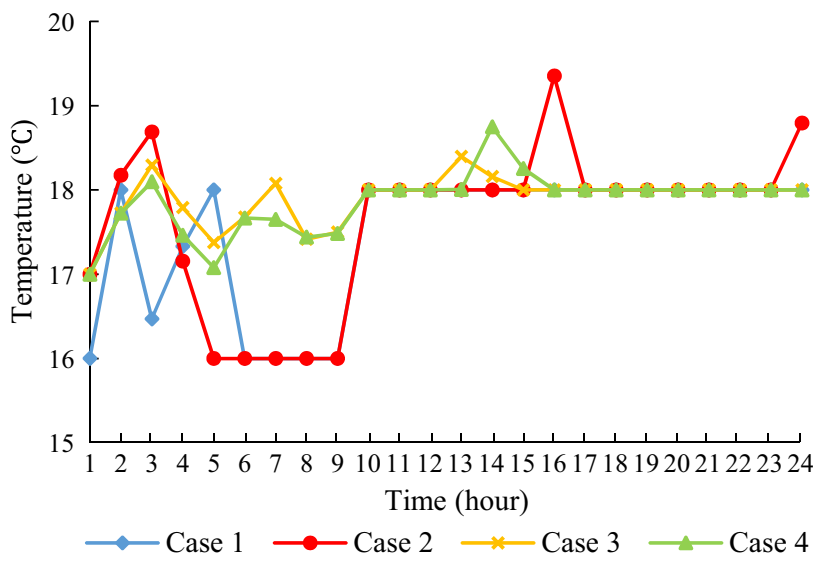

Fig. 15 Indoor air temperature in each case

has a time delay from $T_{\mathrm{w} 1}$ to $T_{\mathrm{w} 3}$ due to the water flow time needed, which is around 2 hours for the whole water supply pipeline.

Fig. 15 shows the indoor air temperature for each case. The lower limit of the indoor temperature is $16^{\circ} \mathrm{C}$ between 1 a.m. and 9 a.m. and $18^{\circ} \mathrm{C}$ after 9 a.m. The indoor temperature varies frequently before 9 a.m. but subsequently remains near $18^{\circ} \mathrm{C}$. Relative to Case 1 , the indoor temperature is at a relatively higher level than that of Case 3 and Case 4, which considers the heat storage ability of heat users.

Fig. 16 shows the heat storage of different mediums in Case 4; positive values indicate that the mediums are storing heat, whereas negative values denote heat release. The cumulative figure indicates whether the system is predominantly storing or releasing heat over each time interval. The building structure has the highest heat storage capacity, reaching almost $400 \mathrm{GJ}$, and the heat capacity of water is slightly lower. The relative storage capacity of the air and pipeline is much smaller.

According to the hourly heat storage of the mediums, more heat is produced and stored at peak hours. During that time, CHP units must run at a higher load and

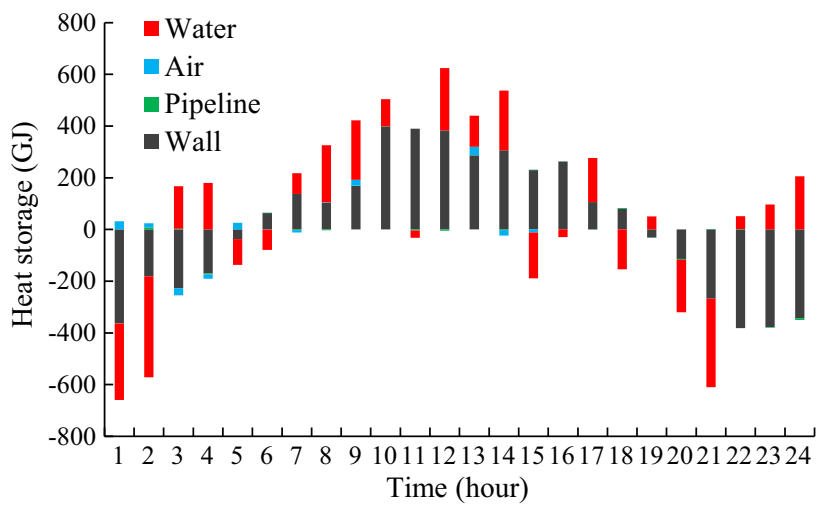

Fig. 16 Heat storage of different mediums in Case 4 


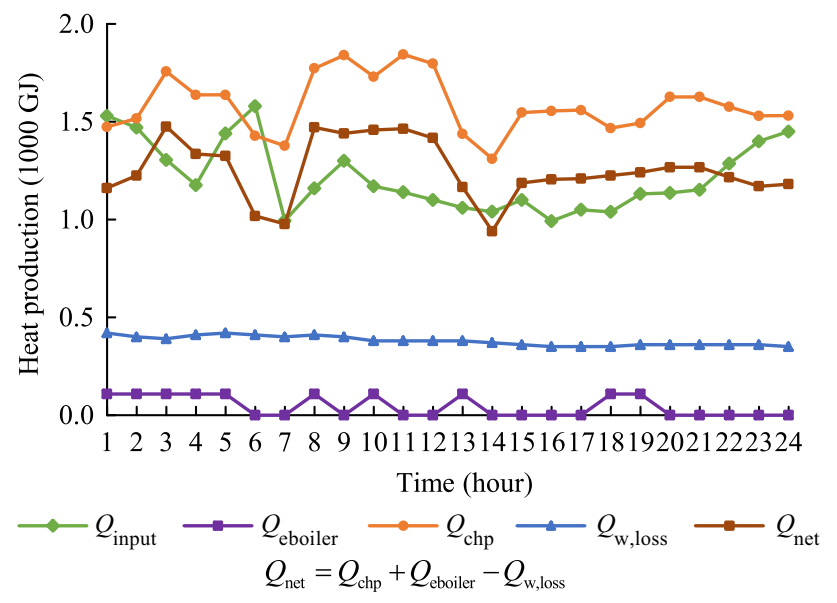

Fig. 17 Heat transport in Case 4

simultaneously produce additional heat. In contrast, the heat is released to the end users in off-peak hours, when the load of the CHP is lower, further reducing coal consumption. Furthermore, the heat released can replace part of the heat supply and reduce the minimum power output of CHP units. Therefore, more wind power is integrated to the grid, and less wind curtailment is achieved.

$Q_{\text {net }}=Q_{\text {chp }}+Q_{\text {eboiler }}-Q_{\mathrm{w}, \text { loss }}$

Figure 17 shows the heat production of CHP units and electric boilers with heat storage tanks, the heat demand of end users in Case 4, and the heat loss of water in the heating network. Relative to the CHP units, the heat production of electric boilers is small, and this is mainly determined by the assumption of the electric boiler capacity in this model. The heat demand of end users is used for heating the indoor air and the buildings, and some is lost as heat dissipation to the outdoors. The virtual variable, $Q_{\text {net }}$, is approximately equal to the heat transported to the end users. If $Q_{\text {net }}$ is larger than $Q_{\text {input }}$, i.e., more heat will be directed to the end users, and some heat will be stored in the walls. If $Q_{\text {net }}$ is less than $Q_{\text {input }}$, i. e., less heat will be directed to the end users, then some heat will be released from the walls to heat the indoor air. These findings are also supported by Fig. 16.

\section{Conclusion}

To reduce the coal consumption and $\mathrm{CO}_{2}$ emissions and integrate additional wind power into the electricity grid in Northeast China, this paper presented an optimization model for the joint dispatch of heat and power by considering the energy storage of electric boilers and the thermal inertia of district heating systems. Based on actual grid data for Northeast China, the proposed method is applied to four cases with/without considering this energy storage capability. The results show that the electric boilers and the thermal inertia of the heating network hold great potential for reducing both coal consumption and wind curtailment.

By introducing electric boilers into the regional heating system, wind curtailment and coal consumption are reduced simultaneously (relative to the reference case). Electric boilers can consume a proportion of the extra wind power directly. As a type of flexible heat source, these boilers could accommodate some of the heat requirements of CHP units, expanding their operational flexibility and integrating additional wind power.

Relative to electric boilers, a consideration of the thermal inertia of district heating systems is effective for coal consumption reduction; however, less wind power curtailment occurs at the given system configuration. When considering both types of energy storage capacities in terms of heat and power dispatching, the coal consumption and wind curtailment are reduced significantly.

The results provide a method for CHP load dispatching to reduce wind curtailment and coal consumption over an optimized time period. In actual grid dispatching, the outdoor temperature and the output of wind power in each day vary considerably, which is a much more complex scenario than was considered in the model. However, it is feasible that we can conduct optimized load dispatching of CHP units when the wind power is strong, integrating additional wind power into the grid. The potential of this method over a longer time period is a topic to be investigated in the future.

Acknowledgements The work is supported by National Key Technology R\&D Program (No. 2015BAA01B01) and State Grid Corporation of China.

Open Access This article is distributed under the terms of the Creative Commons Attribution 4.0 International License (http:// creativecommons.org/licenses/by/4.0/), which permits unrestricted use, distribution, and reproduction in any medium, provided you give appropriate credit to the original author(s) and the source, provide a link to the Creative Commons license, and indicate if changes were made.

\section{References}

[1] Sieminski A (2014) International Energy Outlook 2014. Energy Information Administration, Washington, USA

[2] White House (2014) US-China joint announcement on climate change. http://www.whitehouse.gov/the-press-office/2014/11/ 11/us-china-joint-announcement-climatechange. Accessed 11 Nov 2014

[3] Li JF, Cai FB, Qiao LM et al (2014) China wind power review and outlook. China Renewable Energy Industry Association, Beijing, China 
[4] World Wind Energy Association (2016) The world sets new wind installations record: $63,7 \mathrm{GW}$ new capacity in 2015. http:// www.wwindea.org/the-world-sets-new-wind-installationsrecord-637-gw-new-capacity-in-2015/. Accessed 10 Jan 2016

[5] Li JF, Cai FB, Qiao LM et al (2012) China wind power outlook 2012. China Environmental Science Press, Beijing

[6] Office of the State Council (2015) The energy development strategy action plan (2014-2020). People's Publishing House, Beijing, China

[7] Yang Y, Wu K, Long $\mathrm{H}$ et al (2014) Integrated electricity and heating demand-side management for wind power integration in China. Energy 78:235-246

[8] Zhang Y (2016) Statistic of wind power curtailment in China from 2011-2015. Wind Energy 2:34-35

[9] Lund H (2005) Electric grid stability and the design of sustainable energy system. International Journal of Sustainable Energy 24(1):45-54

[10] Li Z, Wu W, Shahidehpour M et al (2016) Combined heat and power dispatch considering pipeline energy storage of district heating network. IEEE Trans Sustain Energy 7(1):12-22

[11] Li W, Jiang L (2014) Economic evaluation of using curtailed wind power for heating. Rural Electrif 9:51-53

[12] Su K, Gao T, Liu C et al (2014) Research on power system optimal dispatch with wind power central heating. Jilin Electr Power 42(2): 16-19

[13] Chen X, Kang C, O'Malley M et al (2015) Increasing the flexibility of combined heat and power for wind power integration in China: modeling and implications. IEEE Trans Power Syst 30(4):1848-1857

[14] Meibom P, Kiviluoma J, Barth R et al (2007) Value of electric boilers and heat pumps for wind power integration. Wind Energy 10(4):321-337

[15] Papaefthymiou G, Hasche B, Nabe C (2012) Potential of heat pumps for demand side management and wind power integration in the German electricity market. IEEE Trans Sustain Energy 3 (4):636-642

[16] Liu F, Yang X (2014) Micro-grid economic operation contains electric boiler. Adv Mater Res 1070-1072:1297-1301

[17] Liu Q, Zhang Q, Xia XU (2012) Analysis on feasibility of heat storing electric boiler application for energy storage and peak shaving to increase utilization rate of wind power capacity. Huadian Technol 34(9):75-78

[18] Zhang N, Lu X, Mcelroy MB et al (2016) Reducing curtailment of wind electricity in China by employing electric boilers for heat and pumped hydro for energy storage. Appl Energy 184:987-994

[19] Mendaza IDC, Birgitte BJ, Chen Z (2013) Electric boiler and heat pump thermo-electrical models for demand side management analysis in low voltage grids. Int $\mathbf{J}$ Smart Grid Clean Energy 2(1):52-59

[20] Xu MY, Jiang DX (2015) Analysis on energy efficiency and economics of wind heating system. Renew Energy 37(8):42-47

[21] Long HY, Xu RL, He JJ et al (2013) Integrating wind power by utilizing heat load. Acta Energy Solaris Sin 34(4):598-603

[22] Sorensen JR, Sorensen AM (1995) A wind-powered energy production and storing system. US Patent 5436508, 1 Jul 1993

[23] Jiang XS, Jing ZX, Wu QH et al (2013) Modeling of a central heating electric boiler integrated with a stand-alone wind generator. In: Proceedings of IEEE PES Asia-Pacific power and energy engineering conference, Kowloon, China, 8-11 December 2013, pp1-6

[24] Qin B, Fu L, Jiang Y (2005) Electric peak shaving for CHP plant by using thermal inertia of heat supply system. Gas Heat 25 (10):6-8
[25] Qin B, Jiang Y, Fu L et al (2005) Study on test thermal performance of centralized heat-supply system. Gas Heat 25 (11):20-23

[26] Ji W (2014) Modeling and simulation of promoting wind accommodation based on electric heating. Ph D Thesis. Shandong University, Jinan, Shandong, China

Xianzheng HUANG received his B.E. degree from Tsinghua University in 2014. Now he is a graduate student in the Department of Energy and Power Engineering, Tsinghua University. His research focuses on the modeling, analysis and optimization of renewable energy systems.

Zhaofeng XU received his Ph.D. degree from Tsinghua University in 2004. Now he is an assistant professor in the Department of Energy and Power Engineering, Tsinghua University. His research focuses on the modeling, optimization and techno-economic analysis of energy systems.

Yong SUN received his Ph.D. degree from Harbin Institute of Technology in 2009. Now he is a post doctor in Tsinghua University, and also works in the State Grid Jilin Electric Power Co., Ltd. His research focuses on the dispatch, operation and management of new energy system.

Yali XUE received her Ph.D. degree from Tsinghua University in 2005. Now she is an associate professor in the Department of Energy and Power Engineering, Tsinghua University. Her research focuses on the modeling, simulation and control of energy system.

Zhe WANG received his Ph.D. degree from Pennsylvania State University in 2007. Now he is an associate professor in the Department of Energy and Power Engineering, Tsinghua University. His research focuses on the modeling of energy systems and advanced measurement technology.

Zhijun LIU is now a Senior Engineer in the State Grid Jilin Electric Power Co., Ltd. His work and research focuses on the operation and management of power system.

Zhenyuan LI is now a Senior Engineer in the State Grid Jilin Electric Power Co., Ltd. His work and research focuses on the operation and management of power system and new energy system.

Weidou NI is a member of Chinese Academy of Engineering. Now he is a professor in Department of Energy and Power Engineering, Tsinghua University. His research focuses on the sustainable development of China's energy and energy saving. 